\title{
Studies on Protein Multimers
}

\section{THE ASSOCIATION-DISSOCIATION BEHAVIOUR OF $\beta$-GALACTOSIDASE IN GLYCEROL}

\author{
By C. C. CONTAXIS ANd F. J. REITHEL \\ Department of Chemistry, University of Oregon, Eugene, Oreg. 97403, U.S.A.
}

(Received 14 April 1971)

\begin{abstract}
1. The effect of glycerol on the association-dissociation behaviour of $\beta$-galactosidases from Escherichia coli is described. Two strains, K 12 and ML 308, were used as sources of enzyme. The conditions used, involving glycerol at a concentration of $90 \%$, result in dissociation of the active 540000 -dalton form to inactive structural subunits of 135000 daltons. 2. A pH-dependent process, assumed to be cyclic in mechanism, allows reassociation to an active form indistinguishable from the initial protein. 3. The apparently identical structural subunits, if produced in the presence of EDTA, were found to give rise to two electrophoretically distinguishable species. 4. Enzymes from both strains of $E$. coli can be distinguished electrophoretically but exhibit the same behaviour in glycerol. 5. A scheme of the association-dissociation is presented that is consistent with the behaviour observed and that has some predictive value.
\end{abstract}

During the past decade a number of studies have been directed toward establishing the size of structural subunits in $\beta$-galactosidase (EC 3.2.1.23). One strategy has been to modify thiol groups of the protein and to expose the derivative protein to dissociating conditions. Reaction with iodoacetamide and solution in $5 \mathrm{M}$-guanidine hydrochloride resulted in a form estimated as 147000 daltons. Performic acid oxidation and solution in sodium dodecyl sulphate yielded a product reported as a 42000-dalton subunit (Wallenfels, Sund \& Weber, 1963). $N$-Terminal amino acid analyses suggested a 135000-dalton subunit (Steers, Craven \& Anfinsen, 1965). This estimate has been supported by observations on $\beta$-galactosidase in sodium dodecyl sulphate-polyacrylamide-gel electrophoresis (Weber \& Osborn, 1969) as well as by an early estimate of the number of active sites (Cohn, 1957).

Reversible inactivation of the unmodified enzyme in 8 $\mathrm{M}$-urea has been examined (Perrin \& Monod, 1963), but the results were not correlated with dissociation data. Measurement of the sedimentation velocity in $8 \mathrm{M}$-urea led to an estimate of 75000 daltons as the size of the subunit involved in reversible dissociation (Zipser, 1963). Dissociation in 8 $\mathbf{M}$-guanidine hydrochloride resulted in a heterogeneous mixture. The smallest-molecularweight product was estimated as $\mathbf{5 0 0 0 0}$ daltons and the weight-average molecular weight was 80000 (Erickson, 1970).

Our approach to the problem followed from our studies of urease, an enzyme of approximately the same size as $\beta$-galactosidase. Urease exhibits a series of dissociations (Contaxis, 1970; Reithel, 1971) and stepwise dissociation can be observed by a proper adjustment of solvent conditions. The following account is focused on the dissociation behaviour in $90 \%(\mathrm{v} / \mathrm{v})$ glycerol, a process shown for urease to lead to a one-step dissociation without loss of catalytic activity (Contaxis \& Reithel, 1971). $\beta$-Galactosidase, under the conditions described and without modification, quantitatively dissociates to structural units of 135000 daltons. The procedure used resulted in stabilization of the dissociated form in buffer even after removal of the glycerol. This permitted inspection of homogeneity by electrophoresis, determination of molecular weight by sedimentation equilibrium and direct determination of enzymic activity. It was also possible to study the reassociation process and to collect data suggesting a mechanism for associationdissociation and its correlation with changes in enzymic activity.

\section{MATERIALS AND METHODS}

Materials. The $\beta$-galactosidase from Escherichia coli ML 308 was isolated by the procedure of $\mathrm{Hu}$, Wolfe \& Reithel (1959). The $\beta$-galactosidase from $E$. coli $\mathrm{K} 12$ was generously provided by Dr A. S. L. Hu, Department of Biochemistry, University of Kentucky, Lexington, Ky., U.S.A. Both preparations were homogeneous. The buffer systems used were: $0.05 \mathrm{M}$-tris-thioglycollate-1 mM$\mathrm{MgCl}_{2}, \mathrm{pH} 7.0$ and $9.2 ; 0.05 \mathrm{M}$-tris-acetate- $1 \mathrm{mM}-\mathrm{MgCl}_{2}$, pH 7.0 and 9.2;0.05 M-tris-EDTA, pH 7.0 and 9.2, and $0.05 \mathrm{M}$-sodium phosphate-1 $\mathrm{mm}-\mathrm{MgCl}_{2}, \mathrm{pH} 7.0$ and 9.2. 
The tris buffers were made by preparing $0.05 \mathrm{~m}$ solutions of tris, adjusting the $\mathrm{pH}$ to the desired value with thioglycollic acid, acetic acid or $\mathrm{H}_{4}$ EDTA and adding the appropriate amount of $\mathrm{MgCl}_{2}$ when required. The phosphate buffers were prepared by titration of $0.05 \mathrm{M}$ $\mathrm{Na}_{2} \mathrm{HPO}_{4}-1 \mathrm{mM}-\mathrm{MgCl}_{2}$ with $0.05 \mathrm{M}-\mathrm{NaH}_{2} \mathrm{PO}_{4}-1 \mathrm{~mm}-$ $\mathrm{MgCl}_{2}$ to the desired $\mathrm{pH}$. All buffer solutions were made up in deionized water, obtained from a demineralizer column, with a conductivity of $2 \times 10^{-8}-8 \times 10^{-8} \mathrm{ohm}^{-1}$. The reagents used were: tris, A.R. from Sigma Chemical Co., St Louis, Mo., U.S.A.; EDTA, A.R. from Mallinckrodt Chemical Co., St Louis, Mo., U.S.A.; thioglycollic acid (vacuum-distilled) from Evans Chemetics Inc., Waterloo, N.Y., U.S.A.; glycerol and ethylene glycol, spectroquality reagents from Matheson, Coleman and Bell Inc., East Rutherford, N.J., U.S.A.

Enzymic assays. To a $1 \mathrm{ml}$ cuvette was added $1 \mathrm{ml}$ of a substrate solution made by mixing $9 \mathrm{ml}$ of $0.05 \mathrm{~m}$-sodium phosphate buffer, pH 6.95- $0.01 \mathrm{M}-\mathrm{MgCl}_{2}$ with $1 \mathrm{ml}$ of $o$-nitrophenyl $\beta$-galactoside solution $(30 \mathrm{mg} / 10 \mathrm{ml}$ of water). Samples of protein solution were added to produce a linear change in $E_{420}$ between 0.2 and $1 E$ unit/min. A Gilford recording spectrophotometer equipped with a thermostat-controlled cell compartment was used and measurements were made at $20^{\circ} \mathrm{C}$. Activity in units $/ \mathrm{ml}$ was calculated by multiplying the $\Delta E_{420} / \mathrm{min}$ by $5.56 \times 10^{2}$ and the appropriate dilution factors. Activity in units $/ \mathrm{mg}$ could be estimated by determining the protein concentration, where $E_{1 \mathrm{~cm}}^{1 \%}=24$ at $280 \mathrm{~nm}$.

Electrophoresis. The polyacrylamide-gel electrophoresis was carried out in an E-C vertical electrophoresis apparatus (E-C Apparatus Corp., Philadelphia, Pa., U.S.A.). The temperature was maintained constant with water circulating through the apparatus from a thermostat-controlled bath. For the mixing of the buffer in the two chambers a Cole-Palmer oscillating pump was used, regulated by a Variac transformer. For the preparation of the gel the desired amount of Cyanogum-4l (E-C Apparatus Corp.) was dissolved in $100 \mathrm{ml}$ of buffer plus $1 \mathrm{ml}$ of $10 \%(\mathrm{w} / \mathrm{v})$ ammonium persulphate and, to $50 \mathrm{ml}$ of the same buffer in another beaker, $0.1 \mathrm{ml}$ of $N N N^{\prime} N^{\prime}$. tetramethylethylenediamine was added. Both solutions were then mixed well and transferred into the electrophoresis cell for polymerization. A pre run of $2-3 \mathrm{~h}$ under the same conditions as those maintained during the experiment was found to be necessary for the removal of excess of catalyst and for the stabilization of the electrical conductance of the gel. At the end of the run the gel was

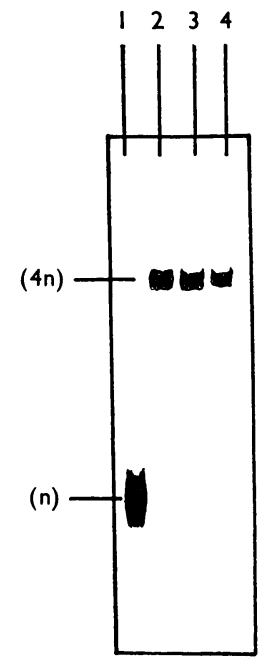

(a)

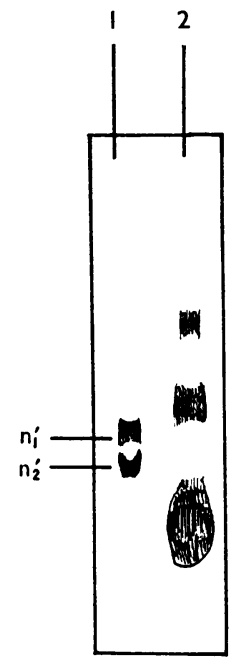

(b)

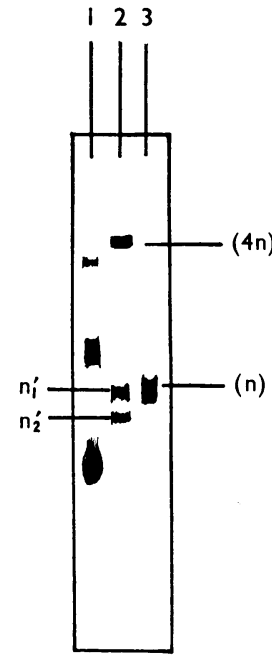

(c)

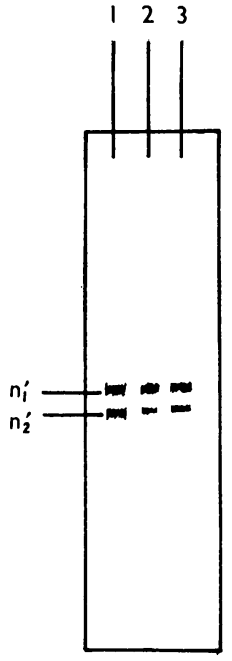

(d)

Fig. 1. Gel-electrophoresis patterns of $\beta$-galactosidase from $E$. coli ML 308. Conditions: $7 \%$ Cyanogum-41; $250 \mathrm{~V} ; 3 \mathrm{~h} ; 20^{\circ} \mathrm{C}$. Electrophoresis buffer: $(a) 0.05 \mathrm{M}$-tris-thioglycollate-1 mM- $\mathrm{MgCl}_{2}, \mathrm{pH} 9.2 ;(b, c, d) 0.05 \mathrm{M}$-trisEDTA, pH 9.2. (a) Band 1, $\beta$-galactosidase after treatment with $90 \%$ (v/v) glycerol in $0.05 \mathrm{M}$-tris-thioglycollate-1 $\mathrm{mM}-\mathrm{MgCl}_{2}, \mathrm{pH}$ 9.2. Band 2, reassociated $\beta$-galactosidase. Band 3 , undissociated $\beta$-galactosidase. Band 4, undissociated $\beta$-galactosidase 10 times diluted. All in $0.05 \mathrm{M}$-tris-thioglycollate-l $\mathrm{mm}-\mathrm{MgCl}_{2}$ buffer, pH 9.2. (b) Band 1, $\beta$-galactosidase (135000 daltons) $n_{1}^{\prime}$ and $n_{2}^{\prime}$, in 0.05 $\mathrm{m}$-tris-EDTA buffer, pH 9.2. Band 2, bovine serum albumin in the same buffer, as reference. (c) Band 1, bovine serum albumin in $0.05 \mathrm{M}$-trisEDTA buffer, pH 9.2, as reference. Band $2, \beta$-galactosidase (540000 daltons) $(4 \mathrm{n})$, partially dissociated in the same buffer, and partially interconverted $n_{1}^{\prime}$ and $n_{2}^{\prime}$. Band 3 , $\beta$-galactosidase (135000 daltons) (n), in $0.05 \mathrm{M}$-tris-thioglycollate-1 mM- $\mathrm{MgCl}_{2}$, $\mathrm{pH} 9.2$ (no interconversion to $\mathrm{n}_{1}^{\prime}$ and $\mathrm{n}_{2}^{\prime}$ ) as reference. (d) Bands $1,2,3, \beta$-galactosidases, $\mathrm{n}_{1}^{\prime}$ and $\mathrm{n}_{2}^{\prime}$, in different degrees of interconversion in 0.05 M-tris-EDTA buffer, pH 9.2. Band 1 , after exposure to $90 \%(\mathrm{v} / \mathrm{v})$ glycerol in $0.05 \mathrm{M}$-tris-EDTA buffer, pH 9.2, for $28 \mathrm{~min}$; band 2 , after $2 \mathrm{~min}$; band 3 , after $5 \mathrm{~min}$. 'The designation $\mathrm{n}_{2}^{\prime}$ was arbitrarily assigned to the band with the higher mobility. 
removed and stained overnight with Amido Black $10 \mathrm{~B}$ and then washed with acetic acid-methanol-water ( $1: 5: 5$, by vol.).

Ultracentrifugation. The instrument used was a Spinco model E ultracentrifuge equipped with a temperature control (RTIC), a Rayleigh interference optical system and an electronic speed control. The fringe patterns were photographed with Spectrographic II-G plates (Kodak) and measured with a microcomparator (Nikon Shadowgraph, model G). For the determination of molecular weights the high-speed sedimentation-equilibrium method (Yphantis, 1964) was used. In the calculation of molecular weight the calculated value of $\bar{v}$ used was 0.76 (Sund \& Weber, 1963). Molecular weights were calculated with the 360/50 computer at the University of Oregon with a program developed in this laboratory.

Optical rotatory dispersion. Measurements were made on a Cary 60 recording spectrophotometer. The temperature was maintained constant at $20^{\circ} \mathrm{C}$ with a Haake-type $\mathrm{F}$ circulator connected to a type $6040221 \mathrm{~cm}$ demountable thermostat-controlled cell. The specific rotation $[\alpha]_{\lambda}^{20}$, at each wavelength $\lambda$, was calculated from the equation $[\alpha]_{\lambda}^{20}=(100 / l \times c) \times \alpha_{\lambda}^{20}$, where $\alpha_{\lambda}^{20}$ is the observed rotation, $l$ is the path length $(\mathrm{dm})$ and $c$ is the protein concentration $(\mathrm{g} / 100 \mathrm{ml})$. For correction of the specific rotation the refractive index of the buffer was assumed to be equal to that of water.

Spectrophotometric measurements. The u.v. spectra and extinction measurements were made with a Cary model 15 spectrophotometer equipped with a thermoregulated cell compartment and thermostat-controlled cell holders. The temperature control was provided by a Haake-type F circulator, in connexion with thermoregulating attachments of the Cary 15 spectrophotometer.

\section{RESULTS}

Studies on the enzyme from E. coli $M L 308$

Electrophoresis. $\beta$-Galactosidase, isolated from strain ML 308, used in this study was homogeneous to the degree shown in band 3 (Fig. $1 a$ ). The small amounts of higher aggregate that formed upon storage did not interfere with interpretation of results. The fast-migrating band 1 (Fig. $1 a$ ) resulted when $\beta$-galactosidase was dissolved in $0.05 \mathrm{M}$-tris-thioglycollate-1 mM-magnesium chloride buffer, $\mathrm{pH} \mathrm{9.2,} \mathrm{to} \mathrm{give} \mathrm{a} \mathrm{solution} \mathrm{of} 4.8 \mathrm{mg} / \mathrm{ml}$ and made $90 \%(\mathrm{v} / \mathrm{v})$ in glycerol at $20^{\circ} \mathrm{C}$. The solution was allowed to stand at $20^{\circ} \mathrm{C}$ for $2 \mathrm{~h}$. The glycerol was removed by dialysis against $0.05 \mathrm{M}$-tristhioglycollate-1 mM-magnesium chloride buffer, pH 9.2. This resulted in a final protein concentration of $0.40 \mathrm{mg} / \mathrm{ml}$ and this sample was used for electrophoresis.

Examination of glycerol-treated enzyme at times shorter than $1 \mathrm{~min}$ revealed the existence of both the starting material and the observed final product but no other intermediates discernible by gel electrophoresis. Enzyme similarly treated with increasing glycerol concentration showed in electrophoresis the formation of the new species only above a sharp transition near $\mathbf{9 0 \%}$ glycerol. In all cases no form with intermediate mobility was observed.

Ultracentrifugation. Samples of enzyme treated with glycerol and transferred into buffer, as above, served for determination of molecular weights. Weight-average molecular weights were calculated for the entire cell from the expression:

$$
M=\left[R T /(1-\bar{v} \rho) \omega^{2}\right] \mathrm{d} \ln [c(r)] / \mathrm{d}\left(0.5 r^{2}\right)
$$

A plot of $\ln [c(r)]$ values against $r^{2}$ shown in Fig. 2 is characteristic of a homogeneous protein solution. At the end of each run the samples were examined by electrophoresis to check for the possibility of permanent changes due to subunit interactions in the concentration gradient of the ultracentrifuge cell. The electrophoretic patterns were identical with those before centrifugation, in agreement with the homogeneity indicated by the linearity of the plot of $\ln [c(r)]$ versus $r^{2}$ shown in Fig. 2. The molecular weights obtained for three different protein concentrations are shown in Table 1. From the comparison of the $\bar{M}_{\mathrm{w}(c=0)}$ and $\bar{M}_{\mathrm{w}(\mathrm{bottom})}$ values for each run and their relation to the $\bar{M}_{\text {w(entire cel1) }}$ homogeneity is evident. By allowing for small differences due to non-ideality, because of the increased electrophoresis interactions at $\mathrm{pH} \mathrm{9.2,}$ we estimate a molecular weight of about 135000 sufficient to characterize the magnitude of the dissociation. This is one-fourth of the molecular weight 540000 reported (Craven, Steers \& Anfinsen, 1965) for the undissociated enzyme.

Reassociation. When the dissociated enzyme in

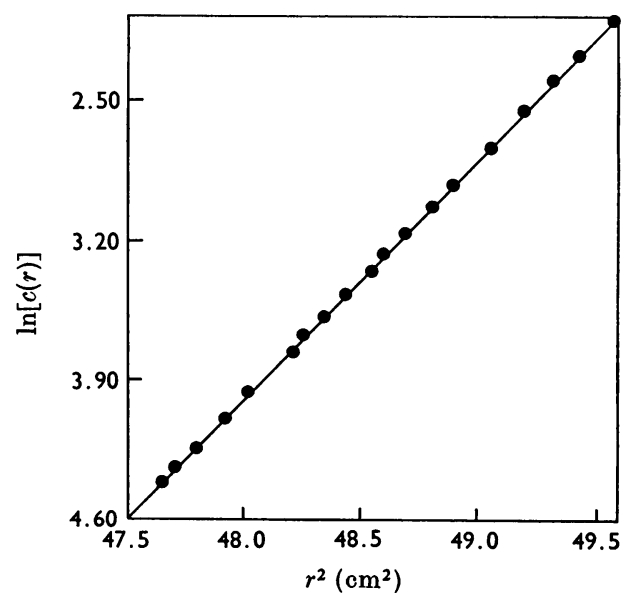

Fig. 2. Sedimentation equilibrium of glycerol-dissociated $\beta$-galactosidase, $\quad 0.04 \%$ in $0.05 \mathrm{M}$-tris-thioglycollate$1 \mathrm{mM}-\mathrm{MgCl}_{2}, \mathrm{pH} 9.2$, after $28 \mathrm{~h}$ at $12500 \mathrm{rev} . / \mathrm{min}, 20^{\circ} \mathrm{C}$. The molecular weight over the entire cell for this plot is $131500 \pm 500$. 
Table 1. Molecular weights of dissociated $\beta$-galactosidase determined by the high-speed sedimentationequilibrium method ( $Y$ phantis, 1964)

$\beta$-Galactosidase, from $E$. coli strain ML308, was dissociated in $90 \%$ glycerol in $0.05 \mathrm{M}$-tris-thioglycollate buffer-1 $\mathrm{mM}_{\mathrm{MgCl}}, \mathrm{MgH}_{2}, \mathrm{pH}$, and dialysed against the same buffer to remove glycerol. The ultracentrifugation conditions were $12000 \mathrm{rev} . / \mathrm{min}$ and $20^{\circ} \mathrm{C}$ for the time indicated.

$\begin{array}{ccccc}\begin{array}{c}\text { Conen. } \\ (\%)\end{array} & \begin{array}{c}\text { Time } \\ (\mathrm{h})\end{array} & \bar{M}_{\text {w (entire cel1) }} & \bar{M}_{\text {w (c=0) }} & \bar{M}_{\text {w (bottom) }} \\ 0.04 & 28 & 131500 \pm 500 & 128400 \pm 2900 & 136300 \pm 3700 \\ 0.02 & 24 & 132100 \pm 500 & 122200 \pm 2700 & 142700 \pm 3000 \\ 0.02 & 48 & 132100 \pm 500 & 124200 \pm 3700 & 140500 \pm 4500 \\ 0.05 & 28 & 138100 \pm 600 & 138200 \pm 6500 & 137600 \pm 8300\end{array}$

buffer solution at $\mathrm{pH} 9.2$ was transferred to $\mathrm{pH} 7.0$ by dialysis against $0.05 \mathrm{M}$-tris-thioglycollate-1 $\mathrm{mm}$ magnesium chloride buffer, $\mathrm{pH} 7.0$, the result was the slower-migrating form in band 2 (Fig. $1 a$ ). The same result was obtained if, instead of tris-thioglycollate buffer, $0.05 \mathrm{M}$-tris-acetate buffer or $0.05 \mathrm{M}$ phosphate buffer, $\mathrm{pH} 7.0$, was used. The migration velocity of this band was found to be the same as the starting material when compared in different gel concentrations and its molecular weight was estimated to be 540000 by sedimentation equilibrium. These observations indicate that the new form represents the reassociated $\beta$-galactosidase. The reassociated form has a specific activity $90-120 \%$ of the starting material, depending on the time after reassociation. It reaches its maximum $2-3 \mathrm{~min}$ after reassociation at $20^{\circ} \mathrm{C}$. When the reassociated $\beta$-galactosidase was exposed to glycerol, dissociation occurred as with the original sample. Glycerol at low concentrations did not inhibit the reassociation. We could repeat the reassociation process even in the presence of $30 \%(\mathrm{v} / \mathrm{v})$ glycerol at $\mathrm{pH}$ 7.0. The reassociation appeared to be a fast process and proceeded without formation of stable intermediates demonstrable by electrophoresis. This was shown by titrating dissociated samples, at $\mathrm{pH} 9.2$, to $\mathrm{pH} 7.0$ and immediately loading on to the electrophoresis gel. Complete reassociation occurred in less than $1 \mathrm{~min}$ at $20^{\circ} \mathrm{C}$. The same reassociation process was observed when $0.02 \mathrm{M}$-tris-acetate or $0.02 \mathrm{M}$-phosphate buffer, $\mathrm{pH} 7.0$, was used.

Enzymic activity. In the presence of $\mathrm{Na}^{+}$and $\mathrm{Mg}^{2+}$, nitrophenyl- $\beta$-galactoside is hydrolysed by $\beta$-galactosidase in the conventional assay procedure in phosphate buffer, pH 6.95. Testing of the dissociated form by this procedure led to negative results but after it had been left to stand under the assay conditions there was evidence of hydrolysis. Since under analogous conditions, that is $\mathrm{pH} 7$ and the same type of buffer, the enzyme reassociates, the observed activity could be due to a reassociated species slowly formed at the extreme dilution required in the assay. An attempt to demonstrate enzymic activity for the dissociated form directly on the gel was also unsuccessful. In this test, 6-bromo-2-naphthyl $\beta$-D-galactopyranoside was the substrate (Burstone, 1962) and no difficulty was experienced in demonstrating activity in the control bands of undissociated enzyme. Tests for the enzymic activity of the dissociated $\beta$-galactosidase in $90 \%(\mathrm{v} / \mathrm{v})$ glycerol have shown that the activity is essentially zero. Interpretation of these results is ambiguous since it is not known whether inactivity is due to a change in the overall structure of the protein or due to an alteration of the enzymesubstrate relationship.

U.v. absorption and optical rotatory dispersion. The u.v.-absorption spectrum of the dissociated $\beta$-galactosidase in the $230-330 \mathrm{~nm}$ region cannot be distinguished from that of the undissociated and reassociated forms when examined in $0.05 \mathrm{M}$-tristhioglycollate-1 mm-magnesium chloride, pH 9.2. A determination of the optical rotatory dispersion was also made in the same buffer. Assuming that the extinction coefficient does not change during the dissociation process, a complete superposition of curves of the undissociated, dissociated and reassociated forms was obtained with a negative Cotton effect at $233 \mathrm{~nm}$.

Effect of $\mathrm{pH}$ variation on the dissociation process. If the 540000 -dalton $\beta$-galactosidase was dissolved in pH 9.2 buffer and checked by electrophoresis over a period of 20 days it showed no trace of dissociation. One of the electrophoretic patterns is shown in band 3 of Fig. 1(a). It is therefore evident that the buffer of pH 9.2 alone, involved in the step after glycerol treatment, did not induce dissociation. In the first step of our dissociation process the enzyme was exposed to $90 \%(\mathrm{v} / \mathrm{v})$ glycerol$0.05 \mathrm{M}$-tris-thioglycollate-1 mM-magnesium chloride, $\mathrm{pH}$ 9.2. Since the $\mathrm{pH}$ is indeterminate in $90 \%$ $(\mathrm{v} / \mathrm{v})$ glycerol it cannot be concluded that a $\mathrm{pH}$ value of 9.2 is essential for the dissociation. To overcome this uncertainty in a parallel experiment a similar buffer at pH 7.0 was used for the dissociation in $90 \%$ glycerol and the treated enzyme was directly loaded on to the electrophoresis gel at 
pH 9.2. Since the glycerol gradually diffuses after loading of the sample, the $\mathrm{pH}$ becomes significant when the glycerol concentration becomes less than $90 \%$. This exposes the enzyme to the higher $\mathrm{pH}$ at a glycerol concentration lower than that required for dissociation, which, as we have pointed out, must be at least $90 \%$. The electrophoretic pattern obtained was identical with that already presented for the enzyme dissociated in buffer of pH 9.2. It is therefore evident that the $\mathrm{pH}$ of the buffer in which the enzyme is dissolved for exposure in $90 \%$ glycerol can vary but maintenance of the dissociated form required a $\mathrm{pH}$ of about 9 after removal of the glycerol. This conclusion is supported by experiments in which the enzyme was dissociated in $\mathrm{pH} 7$ buffer by adding glycerol and then dialysed against pH 9.2 buffer. The result was the 135000 dalton form.

Protein concentration as a factor in the dissociation process. For dissociation under the conditions described a tenfold dilution by glycerol was involved. To check the importance of this factor in the dissociation of $\beta$-galactosidase samples containing the 540000 -dalton form were subjected to electrophoresis in parallel with samples diluted tenfold in the same buffer of pH 9.2. The patterns obtained from the diluted samples did not show any trace of dissociation for periods up to 20 days. A representative electrophoretic pattern is shown in band 4 of Fig. 1 $(a)$. It seems clear that the observed dissociation is not due to the dilution involved.

Type of subunit interactions. The effect of glycerol on $\beta$-galactosidase was studied by using the buffer systems tris-thioglycollate, tris-acetate and phosphate. The behaviour of the protein was identical in each as judged by our criteria. Dissociation and reassociation occurred in the presence and in the absence of free thiol groups, as shown when thioglycollate is present or absent. It is therefore evident that no disulphide bonds are directly involved in the interaction between the subunits. Since our results indicated that dissociation was not a sensitive function of $\mathrm{pH}$ it seems likely that ionic interactions are not important. It is therefore suggested that hydrophobic interactions and hydrogen-bonding forces are those to be most seriously considered.

Evidence for dissimilar subunits. The behaviour of $\beta$-galactosidase as already presented was different when EDTA was included in the buffer of dissociation. Exposure of the enzyme to $90 \%$ (v/v) glycerol-0.05M-tris-EDTA buffer, $\mathrm{pH} \mathrm{9.2,} \mathrm{and}$ removal of glycerol by dialysis against the same buffer, resulted in two distinct bands during electrophoresis. Examples may be seen in Figs. $\mathbf{l}(b), \mathbf{l}(c)$ and $\mathbf{l}(d)$. Examination of these $\beta$-galactosidase species by equilibrium centrifugation yielded the value of 135000 daltons and no evidence of serious heterogeneity. Examination of many gelelectrophoresis patterns, some of which are presented in this paper, led us to postulate the existence of two types of structural subunits present in equal amounts. The evolution of the faster moving of the two is gradual and depends on the time of exposure to glycerol. In $48 \mathrm{~h}$ at $6^{\circ} \mathrm{C}$ the conversion is complete, as shown in Fig. 1(b), band 1. Incomplete conversion after $28 \mathrm{~min}$ exposure or less is shown in Fig. 1 $(d)$. Figure $1(c)$, band 2, shows that undissociated $\beta$-galactosidase, in a partially dissociated sample with $90 \%(\mathrm{v} / \mathrm{v})$ glycerol, was not affected by EDTA as was the dissociated form. Evaluation of the electrophoretic mobility as a function of gel concentration showed that the retardation quotient of the two types of subunits is independent of gel concentration. Hence the two subunits are of the same size but differ in charge. On reassociation the two subunits formed the same reconstituted $\beta$-galactosidase already demonstrated by electrophoresis. Since $\mathrm{Mg}^{2+}$ is not present in this process it is evident that $\mathrm{Mg}^{2+}$ is not required for the reassociation although it is necessary for activity (Reithel \& Kim, 1960; Ullman \& Monod, 1969).

Comparative studies with ethylene glycol. An initial test of the effect of $90 \%(\mathrm{v} / \mathrm{v})$ ethylene glycol on $\beta$-galactosidase indicated a polymerization and inactivation. However, a careful study of the changes that occurred as a function of time showed that dissociation, and presumably a reassociation, preceded aggregation. The time-dependence of what was interpreted as denaturation is illustrated in bands 1-4 in Fig. 3(a). As the time of exposure to ethylene glycol increased, more trailing occurred and more of the sample failed to leave the origin. The electrophoretic patterns in Fig. 3(a) show that at least two distinct changes occurred in $90 \%(\mathrm{v} / \mathrm{v})$ ethylene glycol before inactivation and aggregation. The first step was dissociation to the fast-migrating species, presumably of 135000 daltons, followed by apparent reassociation accounting for the observed trailing in the electrophoretic patterns. If EDTA was included in the buffer, as in Fig. 3(b), a difference in the behaviour of the two kinds of 135000 -dalton subunits became evident. This was shown by a parallel treatment of $\beta$-galactosidase in $90 \%(\mathrm{v} / \mathrm{v})$ ethylene glycol-0.05 M-tris-EDTA buffer, pH 9.2, and $90 \%(\mathrm{v} / \mathrm{v})$ glycerol-0.05 M-tris-EDTA buffer, pH 9.2, followed by immediate electrophoresis. This comparison may be seen in the patterns of Fig. 3(b). Bands 1-5 from ethylene glycol solutions again revealed increasing trailing with time. Bands 6-9 from glycerol solution, in contrast, showed no trailing (no part of the sample remaining at the origin), and two distinct faster-migrating species. The faster of these two, $n_{2}^{\prime}$, was missing from bands 1-5 obtained in ethylene glycol. From 


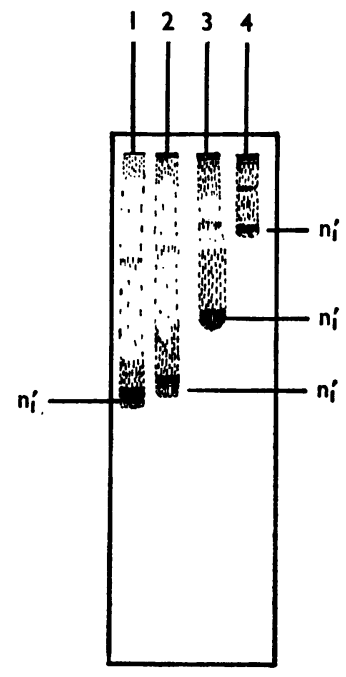

(a)

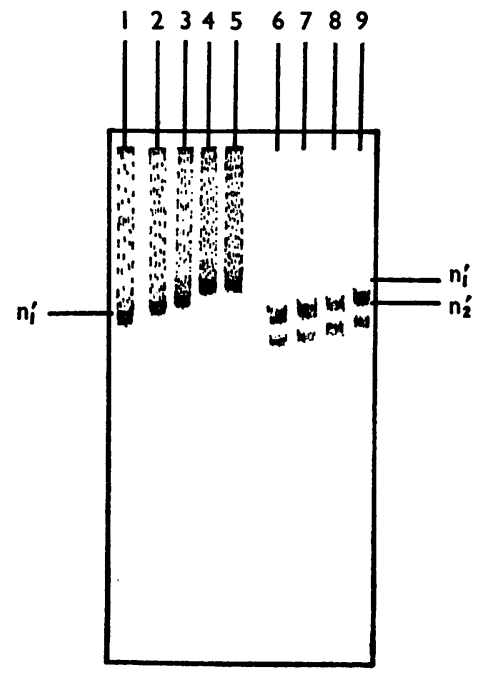

(b)

Fig. 3. Gel-electrophoresis patterns of $\beta$-galactosidase from $E$. coli ML 308 showing the time-course of denaturation in ethylene glycol and comparison with dissociation in glycerol. Conditions: $7 \%$ Cyanogum$41 ; 250 \mathrm{~V}(a), 260 \mathrm{~V}(b) ; 3 \mathrm{~h} ; 20^{\circ} \mathrm{C}$. Electrophoresis buffer: (a) $0.05 \mathrm{M}$-tris-thioglycollate-1 $\mathrm{mM}^{-} \mathrm{MgCl}_{2}$, pH 9.2; (b) 0.05 M-tris-EDTA, pH 9.2. (a) Enzyme exposed to $90 \%$ ( $/ \mathrm{v}$ ) ethylene glycol-0.05 M-tristhioglycollate-l $\mathrm{mM}-\mathrm{MgCl}_{2}$ buffer, $\mathrm{pH}$ 9.2. Samples were loaded serially on to the gel at the times indicated. Band 1, 0.5 min; band 2, 7.5 min; band 3, $57 \mathrm{~min}$; band 4, $115 \mathrm{~min}$. (b) Bands 1-5, enzyme exposed to $90 \%$ $(\mathrm{v} / \mathrm{v})$ ethylene glycol-0.05 M-tris-EDTA, pH 9.2. Samples were loaded serially at the times indicated. Band 1 , $2.5 \mathrm{~min}$; band $2,5 \mathrm{~min}$; band $3,10 \mathrm{~min}$; band 4, $15 \mathrm{~min}$; band 5, $20 \mathrm{~min}$. Bands 6-9, enzyme exposed to $90 \%(\mathrm{v} / \mathrm{v})$ glycerol-0.05 M-tris-EDTA buffer, pH9.2. Samples were loaded serially at the times indicated. Band 6, 2.5 min; band 7, 6 min; band 8, $11 \mathrm{~min}$; band 9, $16 \mathrm{~min}$.

the time-dependence patterns of the dissociations shown in Fig. 3(b) it is evident that the faster migrating of the two distinguishable 135000-dalton subunits is less resistant to denaturation by ethylene glycol. It is denatured as soon as it is formed, showing up as a trace and gradually as an aggregate at the origin of the electrophoretic pattern.

\section{Studies on the enzyme from E. coli $K 12$}

Meticulous gel-electrophoresis studies have revealed that $\beta$-galactosidases, isolated from strains ML 308 and $\mathrm{K} 12$ respectively, can be distinguished. The $\beta$-galactosidase from strain ML 308 shows a slightly but distinctly higher electrophoretic mobility. Previous attempts to differentiate $\beta$-galactosidases from these strains were unsuccessful (Brown, Koorajian, Katze \& Zabin, 1966). Since the amino acid compositions were reported to be the same within experimental error the result reported was not surprising. A sample gel is outlined in Fig. 4. Determination of the retardation quotient at varying gel concentration indicates no difference in size but difference in charge. When enzyme from $\mathrm{K} 12$ was used in place of that from strain ML 308 in the types of experiments described above there was no marked difference in the association-dissociation and activity patterns. We conclude that the behaviour of glycerol and the effect of EDTA are characteristics not restricted to one strain.

\section{DISCUSSION}

We have presented evidence for what we believe to be a reversible dissociation-association of $\beta$-galactosidase by employing 90\% (v/v) glycerol and $\mathrm{pH}$ change in separate steps. The process resembles in many aspects the behaviour of urease in glycerol already reported in detail (Contaxis \& Reithel, 1971; Blattler, Contaxis \& Reithel, 1967), but also shows some special characteristics. Since the dissociation step is not sensitive to $\mathrm{pH}$ changes and does not involve disulphide bonds it is most likely that it involves only hydrophobic interaction and perhaps hydrogen-bonding. The spectral observations indicate no general or marked conformational changes accompanying this process and it is thus probable that the subunit contacts involve only a small fraction of the protein domain. The 


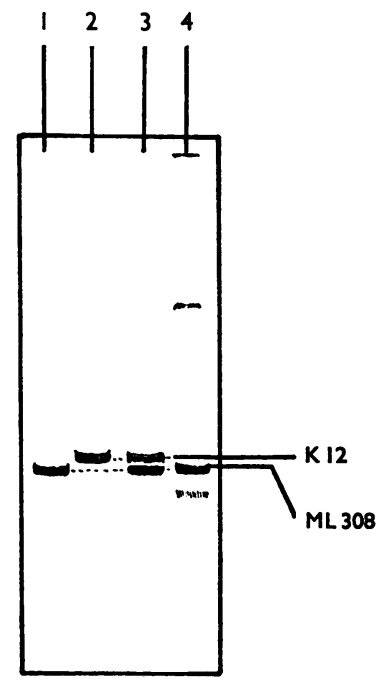

Fig. 4. Electrophoretic differentiation of $\beta$-galactosidases; $E$. coli ML 308 and K 12. Conditions: 7\% Cyanogum-41; electrophoresis buffer $0.05 \mathrm{M}$-tris-EDTA, pH 9.2; $250 \mathrm{~V}$; $3 \mathrm{~h} ; 20^{\circ} \mathrm{C}$. Band 1, strain ML 308; band 2, strain $\mathrm{K} 12$; band 3 , mixture of each $(1: 1, v / v)$; band 4, crude preparation from strain ML 308. All samples were dissolved in 0.05 $\mathrm{M}$-tris-EDTA buffer, pH 9.2.

diminution or loss of the enzymic activity on dissociation is also consonant with a localized conformational change. We have preliminary ultracentrifuge results which suggest that dissociation into dimers occurs under different conditions. It seems likely therefore that the protein has tetrahedral symmetry. The argument for $D_{2}$ point group symmetry is based on the observation that a (2n) form exists and that isologous hydrophobic bonding is more likely than the heterologous bonding required for $\mathrm{C}_{4}$ symmetry. Monod (1969) noted that cyclic symmetries have been strongly disfavoured by natural selection. A recent examination of the tryptic peptides of $\beta$-galactosidase (Fowler \& Zabin, 1970) indicates that the two species of subunits suggested in the present study must be quite similar. No substantial evidence exists for more than one $N$-terminal or $C$-terminal amino acid per 135000 daltons. We propose that subunit structures $n_{1}$ and $n_{2}$ are quasi-identical and that their association into a tetramer with $D_{2}$ point symmetry reflects a kinetic process not severely restricted by shape (Bernal, 1967). The sequence of events for the $4(n) \leftrightarrows(4 n)$ interconversion presented here (where $n=135000$-dalton monomer) is a cyclic process closely resembling that for urease (Contaxis \& Reithel, 1971) and is shown in Scheme 1.

Our interpretation of the scheme follows. For the undissociated tetrameric $\beta$-galactosidase in buffer, pH 7.0, the structural integrity predominantly depends upon non-ionic subunit interactions. On transfer to $90 \%$ glycerol a phase change occurs in which the $\beta$-galactosidase tetramer is surrounded by an environment permitting a change to a more stable form, by solvent interaction, and dissociation occurs. The $\beta$-galactosidase in $90 \%$ glycerol does not necessarily have the same (4n) structure as in buffer, pH 7.0, and we therefore present that as $[(4 \mathrm{n})]$. Its existence was indicated by loading directly on to the electrophoresis gel from $90 \%$ glycerol samples treated for $1 \mathrm{~min}$. In a duplicate experiment $\beta$-galactosidase treated with $90 \%$ glycerol for more than $2 \mathrm{~min}$ showed only the dissociated (n) form in electrophoresis. Direct study of the ( $n$ ) form by sedimentation equilibrium and electrophoresis has been technically inhibited by the high viscosity of $\mathbf{9 0} \%$ glycerol. Our comparative studies of the dissociation in $90 \%$ glycerol with other glycols, for urease, have shown that the enzyme is in the (n) form in the dissociating medium (Contaxis \& Reithel, 1971). In the present study we maintained the $\beta$-galactosidase in the (n) form after removal of glycerol if the $\mathrm{pH}$ was 9.2. Under this condition our studies in electrophoresis and sedimentation equilibrium showed that the enzyme was maintained in the dissociated (n) form and that with EDTA present the $n_{1}$ and $n_{2}$ forms are distinguishable. Since the (n) forms are not known to be exactly the same in buffer and in $90 \%$ glycerol we label as $n_{1}$ and $n_{2}$ the two forms in glycerol and $\mathbf{n}_{1}^{\prime}$ and $\mathbf{n}_{2}^{\prime}$ those in buffer. Since we have not directly observed the (n) forms in glycerol we put them within brackets. We assume that upon transfer into buffer the $(\mathrm{n})$ forms are stabilized owing to a small conformational change. This change cancels upon decrease of the $\mathrm{pH}$ from 9.2 to 7.0 and reassociation occurs. As we have shown, this last process is not reversed by increasing the $\mathrm{pH}$ from 7.0 to 9.2 , or by dilution, showing that the subunit interactions predominate after reassociation. In the scheme as presented the dissociation of $\beta$ galactosidase is a cyclic process. Both exposure to $90 \%$ glycerol and transfer to buffer, $\mathrm{pH} 9.2$, are necessary. For example, if we dilute glycerol to a concentration below $90 \%$ reassociation occurs, if the $\mathrm{pH}$ is 7.0 ; but the enzyme stays in the dissociated (n) form if the $\mathrm{pH}$ is held at 9.2. Small dilution of glycerol around $90 \%$ where the transition occurs should reverse the process of dissociation by the principle of microscopic reversibility. The high viscosity of glycerol has inhibited the study by centrifugation and electrophoresis in this high glycerol concentration.

The dissociation in the presence of EDTA is unique in that two products, believed to be structural subunits, result. As an explanation of the 


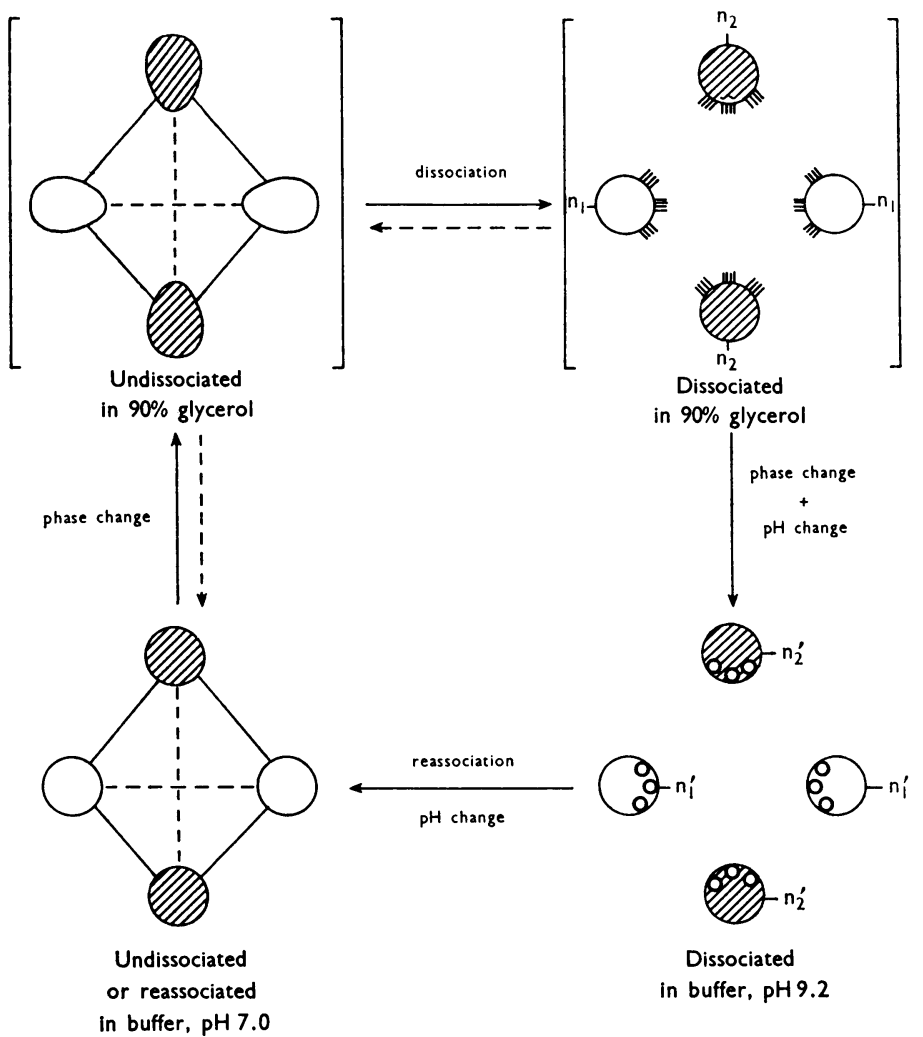

Scheme 1. Diagrammatic representation of the cyclic association-dissociation of $\beta$-galactosidase in $90 \%$ $(\mathrm{v} / \mathrm{v})$ glycerol.

formation of two types of subunits, $n_{1}$ and $n_{2}$, in the presence of EDTA we suggest that they may arise by complex-formation with the $\mathbf{M g}^{2+}$ normally present in the enzyme. This presumptive removal of $\mathbf{M g}^{2+}$ is not evident when the enzyme is in the $(4 n)$ form and may not occur when the subunits are modifying each other. The preferential binding of EDTA to one type of subunit is also possible as an alternative explanation. Since reassociation is not inhibited in the EDTA-dissociated enzyme and the final product of the reassociation is identical with the one obtained on reassociation from EDTA-free buffers, the alternative of EDTA binding is less probable. As we have pointed out, the 540000 . dalton form in band 2 (Fig. $1 c$ ) is a single band whereas the bands corresponding to the dissociated form are double. This also speaks against identical binding of EDTA by (4n) and (n) forms. Whatever the reason, it is evident that half the polypeptide chains in $\beta$-galactosidase are affected by EDTA differently from the other half.

Another instance of the effect of EDTA on association is afforded by Yue, Noltmann \& Kuby
(1969). Here glucose 6-phosphate dehydrogenase, containing no metal, failed to exhibit the expected NADP-induced association reaction in the presence of EDTA. The authors proposed that EDTA exerts its effects by modifying solvent-macromolecule interactions.

Scheme 2 shows that an active (4n) species of $\beta$-galactosidase containing two types of structural subunits, $n_{1}$ and $n_{2}$, must possess at least two types of bonding for structural integrity if the bonding is isologous. In analogy to haemoglobin such a model permits weak interactions between $n_{1}$ units and between $n_{2}$ units. The prediction, in this respect, is that four types of dimers are possible and leads to the speculation that only $n_{1}-n_{2}$ dimers are enzymically active. Our experience with the behaviour of urease in ethylene glycol and glycerol (Contaxis \& Reithel, 1971) has revealed that differentiation can be made between a cyclic reassociation, as in Scheme 1 , and apparent reassociation. The latter occurs in reagents that promote unfolding and represents a process of refolding as well as reassociation. During apparent 


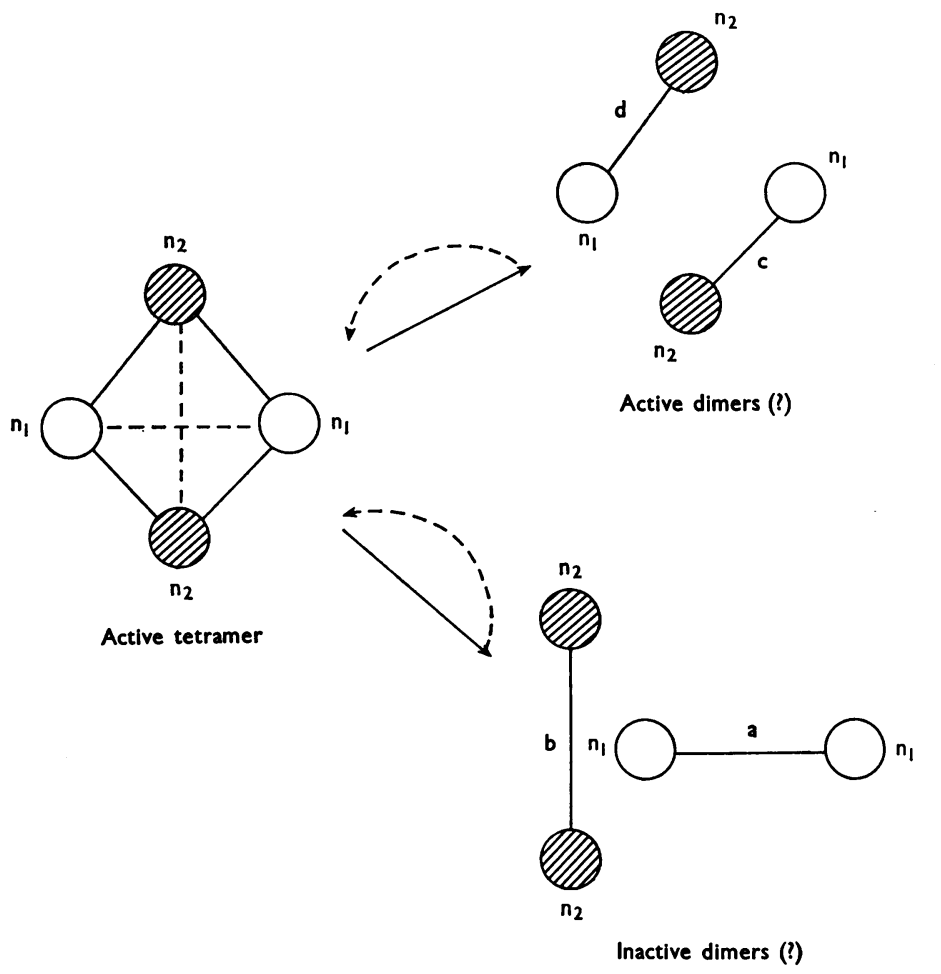

Scheme 2. Possible dimer-tetramer relationships in the association-dissociation of $\beta$-galactosidase.

reassociation species may appear that are not intermediates of the dissociation. This is a process that may lead to the formation of isoenzymes. We have preliminary results which show dissociation to $(2 n)$ species at low ionic strength and high dilution. In this dissociation there is a considerable retention of activity but at least a part of this is due to $(4 n)$ species. An unambiguous demonstration of dissociation of $(4 n)$ to $(2 n)$ species of $\beta$-galactosidase is a subject for future effort.

As noted in the Results section, it is possible to reassociate the 135000 -dalton species to an active tetramer even in the presence of $30 \%$ glycerol. This serves to distinguish the effect of solvents on activity from dissociation phenomena. We have noted superactivity of $\beta$-galactosidase in low concentrations of propanediol (Achee \& Reithel, $1969)$ as well as glycerol. $\beta$-Galactosidases from other organisms (Keen, 1970) have been found to be activated by polyhydroxy compounds. In the studies reported here the activation phenomena, accounting for the observed superactivity of the freshly associated enzyme, may be attributed to perturbation of the tertiary structure.

Reithel \& Kim (1960) showed that $\mathrm{Mg}^{2+}$ is required for activity when $o$-nitrophenyl $\beta$-galacto- side is the substrate, but not when lactose is the substrate. It has also been noted that the concentration of $\mathrm{Mg}^{2+}$ must be kept less than $10^{-2} \mathrm{M}$ for successful refolding of denatured enzyme to a potentially active form. This holds for urea denaturation (Ullman \& Monod, 1969) as well as for glycol dissociation (and denaturation) (Achee $\&$ Reithel, 1969). In such tests for the recording of activity $o$-nitrophenyl $\beta$-galactoside is the substrate normally used. The observation above suggests that $\mathrm{Mg}^{2+}$ might be a stabilizing agent promoting the formation of multiple inter chain bonds. This might, in addition, modify the orderly refolding process. In the presence of lactose as a substrate such stabilization is evidently not needed or it may be provided by the polyhydroxy substrate. However, in the present study no polymerization or precipitation occurred during reassociation despite the presence of $\mathrm{Mg}^{2+}$. We interpret this as evidence that no appreciable unfolding occurs in glycerol although it does not preclude local conformation changes. It is evident that dissociation as such can be responsible for loss of activity and hence provides one more example of structural subunits interacting in association. There is no reason to expect $(n)$ in isolation to possess the same conformation as in 
(4n). Since the above phenomena occur whether $\mathrm{Mg}^{2+}$ is present or not, the problem of $\mathbf{M g}^{2+}$ activation may be considered subsidiary to dissociation and is probably associated with local conformational arrangement.

This investigation was supported by U.S. Public Health Service Research Grant 5 ROI AM 11678 from the National Institutes of Health and by National Science Foundation Grant GB 2513. This paper is based on a portion of a dissertation submitted by C. C. C. to the University of Oregon in partial fulfilment of the requirements for the $\mathrm{Ph} . \mathrm{D}$. degree, June 1970.

\section{REFERENCES}

Achee, F. M. \& Reithel, F. J. (1969). Abstr. Pacific Slope Biochem. Conf., Seattle, p. 7.

Bernal, J. D. (1967). J. molec. Biol. 24, 379.

Blattler, D. P., Contaxis, C. C. \& Reithel, F. J. (1967). Nature, Lond., 216, 274.

Brown, J. L., Koorajian, S., Katze, J. \& Zabin, I. (1966). J. biol. Chem. 241, 2826.

Burstone, M. S. (1962). Enzyme Histochemistry, p. 375. New York: Academic Press Inc.

Cohn, M. (1957). Bact. Rev. 21, 140.

Contaxis, C. C. (1970). Ph.D. Thesis: University of Oregon; Dissert. Abstr. (1971). 31, Order no. 71-1304.
Contaxis, C. C. \& Reithel, F. J. (1971). J. biol. Chem. 246, 677.

Craven, G. R., Steers, E., jun. \& Anfinsen, C. B. (1965). J. biol. Chem. 240, 2468.

Erickson, R. P. (1970). Biochem. J. 120, 255.

Fowler, A. V. \& Zabin, I. (1970). J. biol. Chem. 245, 5032.

Hu, A. S. L., Wolfe, R. G. \& Reithel, F. J. (1959). Archs Biochem. Biophys. 81, 500.

Keen, N. T. (1970). Physiologia Pl. 23, 878.

Monod, J. (1969). Proc. Nobel Symp. no. 11, p. 15. Stockholm: Almquist and Wiksell Forlag.

Perrin, D. \& Monod, J. (1963). Biochem. biophys. Res. Commun. 12, 425.

Reithel, F. J. (1971). In The Enzymes, 3rd ed., vol. 4, p. 1. Ed. by Boyer, P. New York and London: Academic Press.

Reithel, F. J. \& Kim, C. J. (1960). Archs Biochem. Biophys. 90, 271.

Steers, E., jun., Craven, G. R. \& Anfinsen, C. B. (1965). J. biol. Chem. 240, 2478.

Sund, H. \& Weber, K. (1963). Biochem. Z. 337, 24.

Ullman, A. \& Monod, J. (1969). Biochem. biophys. Res. Commun. 35, 35.

Wallenfels, K., Sund, H. \& Weber, K. (1963). Biochem. Z. 338, 714.

Weber, K. \& Osborn, M. (1969). J. biol. Chem. 244, 4406. Yphantis, D. A. (1964). Biochemistry, Easton, 3, 297.

Yue, R. H., Noltmann, E. A. \& Kuby, S. A. (1969). J.biol. Chem. 244, 1351.

Zipser, D. (1963). J. molec. Biol. 7, 113. 